\title{
Single plant selection for improving root rot disease (Phytophthora medicaginis) resistance in Chickpeas (Cicer arietinum L.)
}

\author{
John Hubert Miranda
}

Received: 19 December 2017 / Accepted: 1 March 2019/Published online: 10 April 2019

(C) The Author(s) 2019

\begin{abstract}
The root rot caused by Phytophthora medicaginis is a major disease of chickpea in Australia. Grain yield loss of 50 to $70 \%$ due to the disease was noted in the farmers' fields and in the experimental plots, respectively. To overcome the problem, resistant single plants were selected from the National Chickpea Multi Environment Trials (NCMET) - Stage 3 (S3) of NCMET-S1 to S3, which were conducted in an artificially infected phytophthora screening field nursery in the Hermitage Research Station, Queensland. The inheritance of resistance of these selected resistant single plants were tested in the next generation in three different trials, (1) at seedling stage in a shade house during the offseason, (2) as bulked single plants and (3) as individual single plants in the disease screening filed nursery during the next season. The results of the tests showed that many of the selected single plants had higher level of resistance and seed yield $(P<0.05)$ than the best resistant cultivars used as checks. The single plants with bidirectional expression of anthocyanin pigment, both at the shoot apex and at the base of stem, showed higher level of resistance than plants without it. The
\end{abstract}

J. H. Miranda ( $\square)$

Hermitage Research Station, Warwick, Australia

e-mail: john_miranda@hotmail.com

J. H. Miranda

Department of Agriculture, Forestry and Fisheries (DAFF),

Brisbane, QLD, Australia results also indicated certain level of heterozygosityinduced heterogeneity, which could cause higher levels of susceptibility, if the selected single plants were not screened further for the disease resistance in advanced generation/s. The genetics of resistance to PRR disease was confirmed as quantitative in nature.

Keywords Polygenic $\cdot$ Back cross $\cdot$ Disease management - Interspecific crosses - Disease resistance $\cdot$ Breeding method $\cdot$ Selection technique . Heterozygosity $\cdot$ Heterogeneity

\section{Introduction}

Chickpea is an important cash crop of Australia, grown during winter for its grain and agronomic value. Phytophthora root rot (PRR) disease is caused by the oomycete pathogen Phytophthora medicaginis and it is an important chickpea biotic production constraint in Australia. No viable control measure exists for PRR disease. Ecologically, the least preferred chemical control using Metalaxyl is only partly effective (Rhodes and Mayer 1989). A bio-control using endophytic actinobacteria that was reported by Misk and Christopher (2011) was only in the early stages of development.

The PRR is most prevalent under cool, prolonged wet conditions and in waterlogged soils. Yield losses due to the disease have been observed from $50 \%$ in 
farmers' fields (Knights et al. 2008) to $70 \%$ in the HRS field experimental plots during 2009. The symptoms include yellowing of lower leaves defoliation from the ground upwards and/or wilting of entire plants, decay of lateral and tap roots, and dark brown to black tap root lesions sometimes extending above ground level (Vock et al. 1980). The peak of disease symptoms appears generally after flowering or podding stage.

As breeding resistant varieties is the most efficient means to overcome the disease problem, the resistance-breeding work by the national chickpea improvement program identified one variety-CPI 56564 (ICC 11870), which had resistance at low, moderate and severe disease conditions. The released varieties developed from this, like Barwon, Norwin, Jimbour, Moti, Yorker, and Kyabra showed only moderate level of resistance (Brinsmead et al. 1985). The high level of resistance revealed in wild species like Cicer echinopermum, C. reticulatum and $C$. judaicum, were incorporated in the present national breeding program (Knights et al. 2008).

The National Pulse Development Program (NPDP) evaluated chickpea genotypes for PRR disease resistance in field nursery that were infected with nine strains, namely 4019, 4021, 4026, 4027, 4046, 4065, 4091, 1129-1 and $943 \mathrm{c}-1$, of the pathogen every season, as part of the national chickpea multienvironment trials (NCMET). These strains were collected from chickpea and lucerne (an alternate host of the pathogen) fields. A large variation in pathogenicity among four strains of the nine was reported later (Du et al. (2013). The information on the strains and inoculation methods used in NCMET were shown in the next section of this article.

The above national screening trials were conducted over three successive years as stage one to three (NCMET - S1 to S3) using advanced generation lines (F5 to F8) originating from single seed descents. These single seed descents that originated from the hybrids of above root rot disease resistant genotypes and high yielding popular cultivars of Australia. As per the national chickpea breeding project specification and framework, samples of each F4 progeny and advanced breeding lines (F5 to F8), which originated from single seed descent selection and samples of all genotypes from multi-environment yield trials (MET) were screened in three cycles in the PRR nursery (NCMET S1 to S3) at the research station every season. It appears that these genotypes from single seed descend selection were promoted to NCMET with the unstated hope that the disease was controlled by one single gene. Whole plot scoring was practiced in NCMET for identifying the resistant entry and the trial was discarded after scoring. The national program promoted genotypes, which had the disease resistant score that was equal or better than that of the standard resistant check variety Jimbour. The varieties grown in farmer's fields, after screening in PRR nursery, had only moderate level of resistance. However, there were many resistant plants in many plots of the trail/s. The vigorous growth and seed yield of these resistant plants inspired the author to select single plants and test their inheritance of resistance in the breeding program.

Crop plant disease resistance is often classified as qualitative and quantitative resistance (Vander plank 2012). The qualitative disease resistance is generally regulated by a single resistance $(\mathrm{R})$ gene, where a classic gene-for-gene mechanism operates, and the inheritance is said to be qualitative or Mendelian. In contrast, many genes of small cumulative effect usually regulate quantitative resistance and the inheritance is stated as quantitative or polygenic (Parlevliet 2002). However, the separation between these two classifications of disease resistance is not clear-cut (Poland et al. 2009). In many crop plants, disease resistance varies from effects of single gene; dominant or recessive to many genes, polygenic or quantitative genes. For an example, resistance to Ascochyta blight in chickpea is controlled by single dominant gene, digenic to quantitative genes depending on the race of pathogen and the cultivar used to study the inheritance of resistance (Sharma and Ghosh 2016).

Du et al. (2013) discovered differential pathogenicity among four isolates of the pathogen (4019, 4021, 4027 and 4046) on three chickpea varieties (Jimbour, Flipper and Yorker). They also screened 16 chickpea genotypes including Yorker and Jimbour derived from crosses involving wild species, using the most aggressive isolate of $P$. medicaginis - 4027. They concluded that there was no chickpea genotype, which was highly resistant to the PRR. They indicated that the variable level of resistance existed among cultivars may be combined in breeding programs. Plett et al. (2016) reported that "Chickpea varieties with improved resistance to Phytophthora also displayed lower colonization by rhizobial bacteria and mycorrhizal fungi, 
would lead to an increased reliance on $\mathrm{N}$ and $\mathrm{P}$ from soil".

Flavonoids are plant secondary metabolites that contribute to the adaptation of plants to biotic (Dixon 2001; Liu et al. 2013) and abiotic stresses tolerance (Smile and Hetherington 1999). The role of anthocyanin pigmentation, a major flavonoid compound, in biotic and abiotic stress tolerance of crop plants were reported by Nicholson and Hammerschmidt (1992), Wegulo et al. (1998), Kolkman and Kelly (2000), Steyn et al. (2002), Treutter (2006), Li et al. (2009), Bovy et al. (2007), Maddox et al. (2010), Liu et al. (2013), Bodah Eliane (2014), Rosado-Álvarez et al. (2014) and Lu et al. (2017). The genes controlling the production of this metabolite have been used in Biotechnology to alter important agronomic traits, such as flower and fruit colour, resistance and nutritional value. The advances made in engineering the flavonoid pathway in tomato (Solanum lycopersicum) was examined by Bovy et al. (2007). Liu et al. (2013) reviewed the abiotic and biotic stress response of flavonoids in cereal crops, Maddox et al. (2010) against bacterial phytopathogen Xylella fastidiosa, under in vitro agar dilution assay conditions. Antifungal properties of plant extract rich in flavonoid compounds were reported by Rosado-Álvarez et al. (2014) for the first time.

The mechanism involved in the pathogenesis of PRR and the genes involved were characterised for some species. The infection took place through direct penetration at root level (Walton 1994; Tyler 2007). Götesson et al. (2002) identified up to 19-member gene family of endopolygalacturonase in Phytophthora cinnamomi. However, genomic level studies during the early stages (2-4 h) of infection of phytophthora in soybean activated more than 195 genes (Narayanan et al. 2009) and eight Quantitative Trait Loci (QTL) for PRR tolerance (Li et al. 2010).

In many crops, single plant selection for various traits were very effective over other methods of selection, purely due to genetic reasons. Single plant selection was utilized effectively for seed yield in wheat (Thakare and Qualset 1978) and in durum wheat (Mitchell et al. 1982), for seed yield in lentil for organic farming environment (Vlachostergios et al. 2011), for Fusarium wilt disease resistance in chickpea (Haji-Allahverdipoor et al. 2011), for resistance (Shaikh et al. 2013) against Anthracnose (Collitotrichum truncatum) of lentils (Lens culinaries) and against number of diseases in tomato (Hanson et al. 2016), which included yellow leaf curl disease (begomoviruses), late blight (Phytophthora infestans), bacterial wilt (Ralstonia solanacearum) gray leaf spot (Stemphyllium spp.), Fusarium oxysporum f. sp. lycopersici race 2 and Tobacco mosaic virus.

The objectives of this study were (1) to test the inheritance of disease resistance of the selected single plants from the PRR disease nursery, (2) to investigate the possible cause of high levels of disease susceptibility over generations (3) to study the conceivable effectiveness of single plant selection for stable resistance and yield over successive farming.

\section{Materials and method}

The materials for this investigation were the seeds of single plants that were found resistant to the Phytophthora root rot disease in the plots (Figs. 1, 2) of a NCMET-S3. Such trials (NCMET-S1 to S3) were conducted in the artificially infected field nursery of Hermitage Research Station (HRS), Queensland every season.

The NCMET-S3 was planted in the artificially infected field nursery in a Row Column Design (Alpha lattice) consisting of 25 test entries including 5 checks in $1-\mathrm{m}$ row plots. The row spacing was $67 \mathrm{~cm}$. Twenty-five seeds were planted per row. The seeds were inoculated with a mixture of nine strains of $P$. medicaginis at the rate of $\approx 10,000$ oospores/seed applied in slurry, at the time of planting*. A device attached with the tractor, coated each seed with the homogenised mixture of media (slurry) containing the nine strains of the pathogen, while falling from the seed tray. The nine strains were-4019, 4021, 4026, 4027, 4046, 4065, 4091, 1129-1 and 943 c-1. These strains were cultured and inoculated every season in collaboration with the Department of Primary Industries (DPI) New South Wales and DAFF, Queensland. The trial was flood irrigated during flowering to enhance the spread of the pathogen in the field (Figs. 1,2). The standard cultural and plant protection practices were implemented when required. (Note: A detailed information about the strains, spore production technique and concentrations, may be obtained from Phytophthora Officer in the Department of Agriculture, New South Wales Australia). 

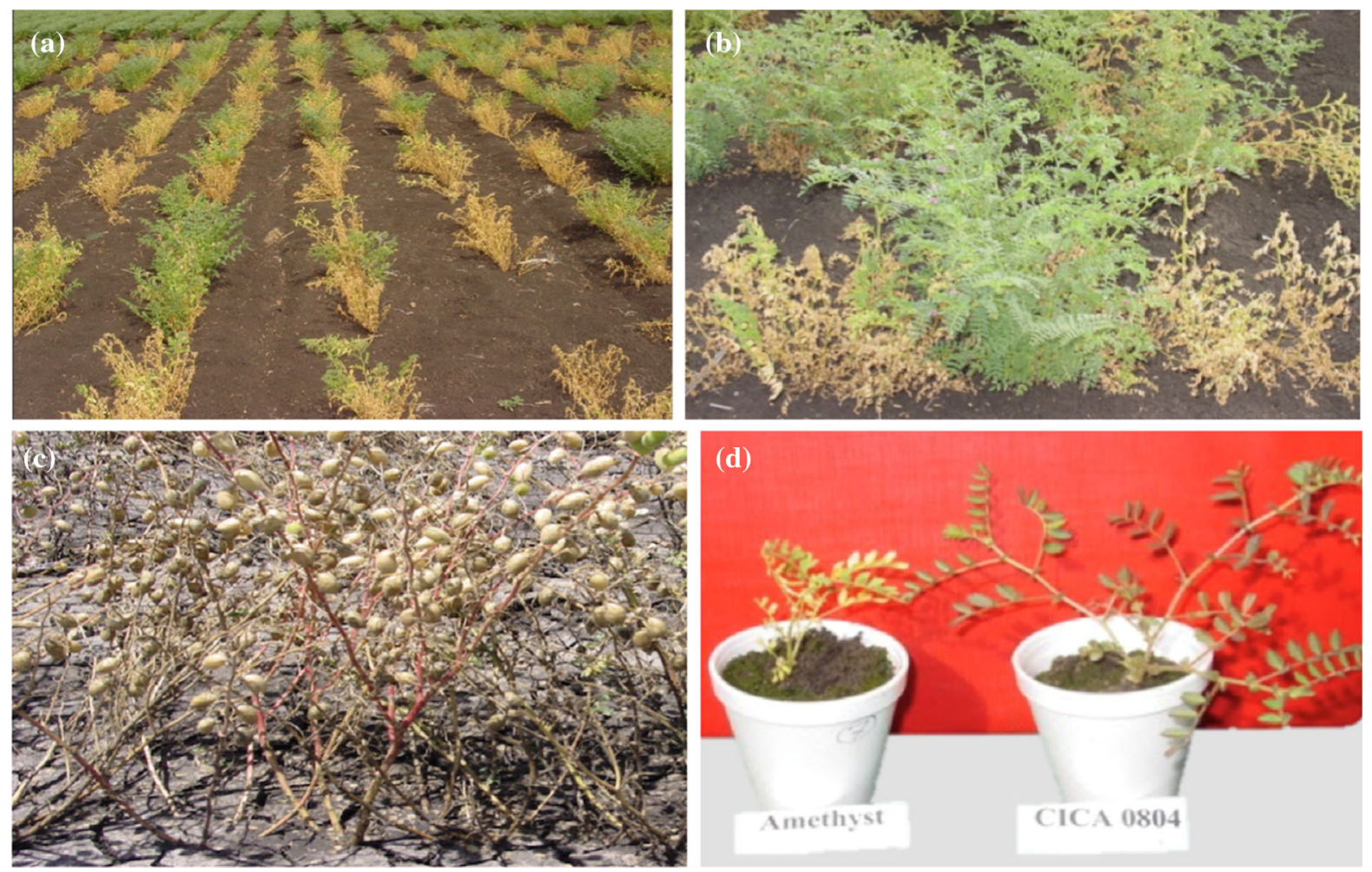

Fig. 1 Phytophthora root rot susceptible and resistant chickpea plants at Hermitage Research Station, Department of Agriculture and Fisheries, Queensland. a A general view of chickpea root rot disease screening field nursery at flowering stage. b A resistant plant within a row of chickpea in the field PRR disease screening nursery at flowering stage. c Resistant anthocyanin pigmented single plant with large number of healthy pods. He

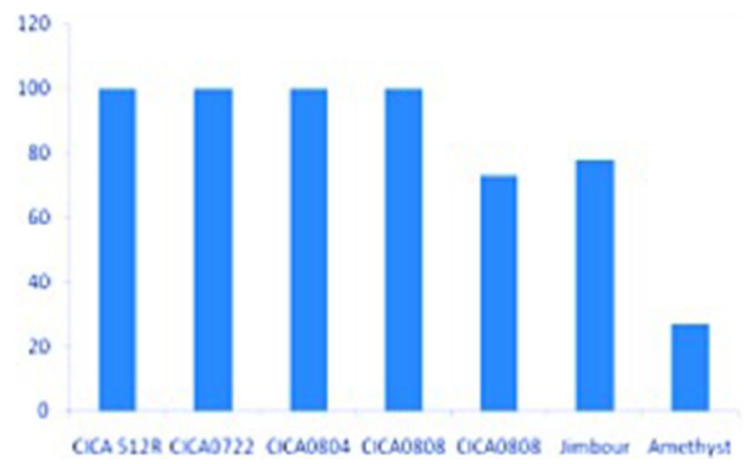

Fig. 2 Summary of three tests at seedling stage conducted in the shade house; the percentage of seedlings survived up to 23 days is on the $\mathrm{Y}$ axis and the genotypes of the selected resistant single plants and standard controls on $\mathrm{X}$ axis

Many resistant plants were noticed in the plots of disease nursery by end the season's NCMET-S3 trial (Figs. 2, 3). The resistant single plants were selected

lower stem is covered with mud due to field flooding by rain during harvest time. d Chickpea plants showing susceptibility and resistance to phytophthora root rot at seedling stage. Amethyst, the susceptible genotype on the left and the resistant genotype, CICA 0804 on the right, after three weeks of growth in PRR infected soil

based on the pod number and healthy tap root system that was assessed after pulling the plants out of the soil, which was saturated with water (as there was heavy rain). The inheritance of resistance to the disease was tested by growing the seeds of the selected disease resistant plants during off-season in a shade house and in the field screening studies during the next season.

\section{Seedling test in a shade house}

The inheritance of the disease resistance was first tested on seedlings in the shade house. Three-day-old germinated chickpea seeds were planted at the rate of one seedling per $50 \mathrm{~mL}$ Styrofoam cup containing the $P$. medicaginis infected soil (Fig. 4), which was expected to have sufficient inoculum load to cause infection. This soil was collected at random from the 
Fig. 3 Heat map indicating seed yield in each plot, darker color (red) showing higher seed yield to lighter color (whiter) showing lower seed yield for replication 1 in (a) and replication 2 in (b) of Alpha Lattice field trial. The field variability was distributed
R 1

\begin{tabular}{|c|c|c|c|c|c|}
\hline$R \boldsymbol{V} / \mathrm{C} \rightarrow$ & $\mathbf{1}$ & $\mathbf{2}$ & $\mathbf{3}$ & $\mathbf{4}$ & $\mathbf{5}$ \\
\hline $\mathbf{1}$ & 9 & 11 & 19 & 1 & 5 \\
\hline $\mathbf{2}$ & 18 & 16 & 12 & 8 & 3 \\
\hline $\mathbf{3}$ & 2 & 21 & 13 & 17 & 15 \\
\hline $\mathbf{4}$ & 24 & 14 & 22 & 10 & 7 \\
\hline $\mathbf{5}$ & 6 & 4 & 25 & 23 & 20 \\
\hline
\end{tabular}

SPB trial Wtg with Rep $=1$

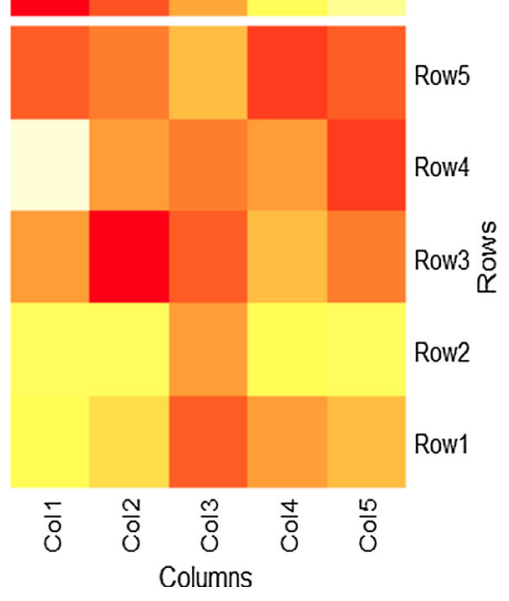

(a)
R2

\begin{tabular}{|c|c|c|c|c|c|}
\hline $\mathrm{R} \boldsymbol{} / \mathrm{C} \boldsymbol{\rightarrow}$ & $\mathbf{1}$ & $\mathbf{2}$ & $\mathbf{3}$ & $\mathbf{4}$ & $\mathbf{5}$ \\
\hline $\mathbf{1}$ & 25 & $\mathbf{1 8}$ & 11 & 7 & 17 \\
\hline $\mathbf{2}$ & 14 & 23 & 3 & 2 & 19 \\
\hline $\mathbf{3}$ & 8 & 5 & 13 & 4 & 24 \\
\hline $\mathbf{4}$ & 15 & 22 & 6 & 1 & 16 \\
\hline $\mathbf{5}$ & 9 & 21 & 10 & 12 & 20 \\
\hline
\end{tabular}

\section{SPB trial Wtg with Rep $=2$}

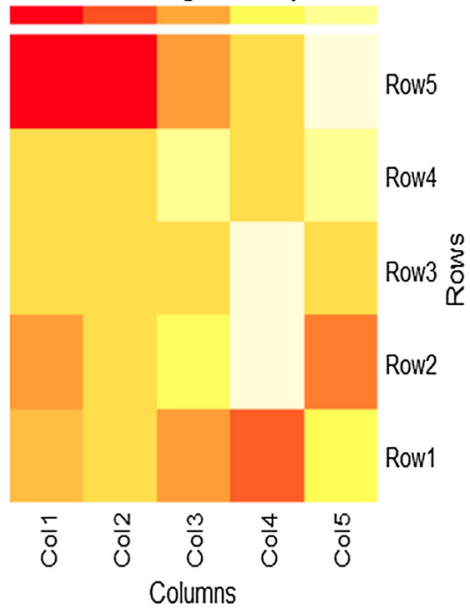

(b) disease nursery at root depth, soon after (within 30 days) the season and thoroughly mixed before using for this test. The field soil was considered as a source of virulent pathogen to infect the test plants because the field nursery was inoculated every season with the nine strains of the pathogen and the propagules of the pathogen had the ability to survive in the field soil for many months (Stack and Miller 1985) to 3-4 years (Manning et al. 2000).

The $50 \mathrm{~mL}$ Styrofoam cups were perforated with a hole at the centre of the base and two triangular cuts on sides of the base to facilitate easy water movement from a two-inch pan. Five styrofoam cups for five replications of a treatment were placed in each pot base pan. The soil was saturated with the water from the pan throughout the experiment (3 weeks). The seeds of selected five single plants with a susceptible check, Amethyst (Fig. 4) and a standard resistant check, Jimbour were tested in the test design. A randomised design was used for the five treatments. The five treatments with five replications were repeated three times. The disease symptoms of entries in the tests were visually confirmed with photographs and descriptors, mentioned earlier in this section as described by Vock et al. (1980).

Screening in the field disease nursery

\section{Screening of single plant bulks in the field trial}

The first field experiment comprised of seeds from 18 single plant bulks and seven cultivars as checks. As seeds from many selected single plants were not enough for a replicated field trial, the seeds from the selected single plants were bulked according to the family of origin. Only the single plants with similar morphological traits like seed shape, size and colour were considered for bulking to form an entry for the first field experiment. These bulks originated from 10 genotypes developed from crosses involving phytophthora resistant parents. This experiment was laid out in a $5 \times 5$ Row Column (Latinised Alpha Lattice) design in 1-m four row plots with two replications, each row was planted with 25 seeds and the row spacing was 


\begin{tabular}{|l|l|l|l|l|l|l|l|}
\hline $\mathrm{R} \boldsymbol{V} / \mathrm{C} \rightarrow$ & $\mathbf{1}$ & $\mathbf{2}$ & $\mathbf{3}$ & $\mathbf{4}$ & $\mathbf{5}$ & $\mathbf{6}$ & $\mathbf{7}$ \\
\hline $\mathbf{1}$ & 32 & 29 & 47 & 38 & 41 & 23 & 45 \\
\hline $\mathbf{2}$ & 16 & 24 & 27 & 17 & 2 & 30 & 37 \\
\hline $\mathbf{3}$ & 39 & 11 & 3 & 49 & 10 & 34 & 40 \\
\hline $\mathbf{4}$ & 20 & 36 & 5 & 28 & 4 & 43 & 33 \\
\hline $\mathbf{5}$ & 26 & 7 & 19 & 12 & 9 & 13 & 44 \\
\hline $\mathbf{6}$ & 48 & 18 & 35 & 6 & 46 & 25 & 31 \\
\hline $\mathbf{7}$ & 22 & 21 & 42 & 14 & 8 & 1 & 15 \\
\hline
\end{tabular}

\begin{tabular}{|l|l|l|l|l|l|l|l|}
\hline$R \boldsymbol{R} / \mathrm{C} \rightarrow$ & $\mathbf{1}$ & $\mathbf{2}$ & $\mathbf{3}$ & $\mathbf{4}$ & $\mathbf{5}$ & $\mathbf{6}$ & $\mathbf{7}$ \\
\hline $\mathbf{1}$ & 23 & 49 & 22 & 30 & 4 & 25 & 7 \\
\hline $\mathbf{2}$ & 37 & 36 & 26 & 45 & 42 & 35 & 40 \\
\hline $\mathbf{3}$ & 15 & 48 & 19 & 2 & 10 & 38 & 28 \\
\hline $\mathbf{4}$ & 16 & 18 & 12 & 41 & 34 & 5 & 1 \\
\hline $\mathbf{5}$ & 13 & 24 & 46 & 8 & 32 & 43 & 39 \\
\hline $\mathbf{6}$ & 27 & 14 & 9 & 47 & 20 & 6 & 11 \\
\hline $\mathbf{7}$ & 44 & 17 & 33 & 3 & 21 & 31 & 29 \\
\hline
\end{tabular}

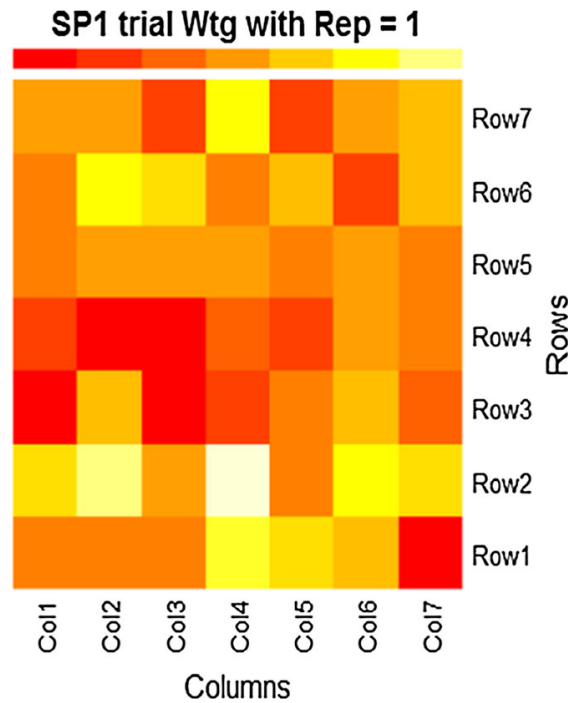

(a)

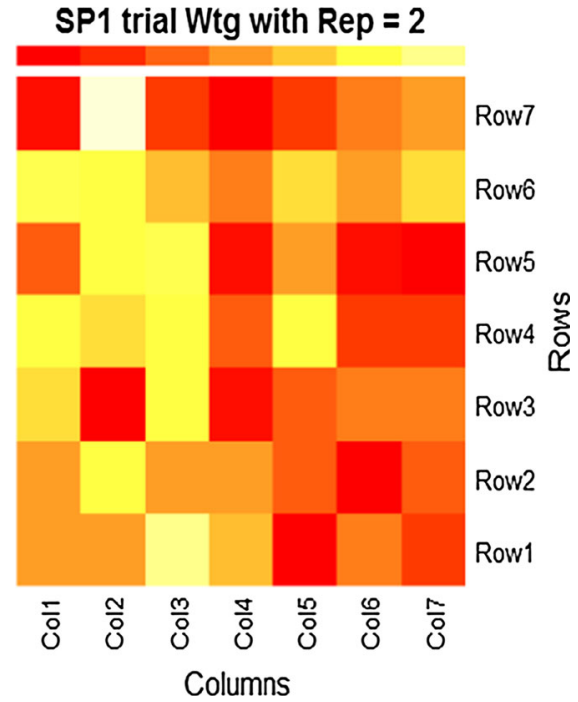

(b)

Fig. 4 Heat map indicating seed yield in each plot, darker color (red) indicate for higher seed yield to lighter color (whiter) indicate lower seed yield for replication 1 in (a) and replication 2 in (b) of Alpha Lattice field trial. The field variability was distributed

$67 \mathrm{~cm}$. The randomization for the $5 \times 5$ row column design is shown in "Appendix 1".

\section{Screening of single plants in the field trial}

The second field trial was made up of seeds of 46 resistant single plants and three cultivars as checks. These single plant entries originated from 17 parental genotypes derived from crosses involving resistant parent. These were laid out in a $7 \times 7$ Row Column (Latinised Alpha Lattice) design in 1-m two row plots with two replications, each row was planted with 25 seeds and the row spacing was $67 \mathrm{~cm}$. The randomization for the $7 \times 7$ row column design is shown in "Appendix 3".
The seeds of the above two trials were inoculated with the same nine strains of the pathogen, exactly the way the NCMET-S3 were inoculated, as mentioned above in the second paragraph of this Materials and Method section. The following general statistical model for response plot yield (considered as nonorthogonal) and disease scores after transformation (non-orthogonal) were analysed in the SAS or R programs. As per this model rows and columns considered as having random effects and the treatment considered as having fixed effects.

$\mathrm{Y}_{\mathrm{ij}}=\mu+\mathrm{r}_{\mathrm{i}}+\mathrm{c}_{\mathrm{j}}+\mathrm{p}_{\mathrm{k}(\mathrm{ij})}+\mathrm{t}_{\mathrm{k}(\mathrm{ij})}+\varepsilon_{\mathrm{ij}}$

where $Y_{i j}=$ Observed disease susceptibility/grain yield, $\mu=$ Overall susceptibility/grain yield mean, $r_{i}=$ Row effect, $c_{j}=$ Column effect, $p_{k(j)}=$ Replication 
variation, $\mathrm{t}_{\mathrm{k}(\mathrm{ij})}=$ Treatment variation and $\varepsilon_{\mathrm{ij}}=$ Random unit variation -independently normally distributed with mean zero and variance $\sigma^{2}$.

\section{Observations and analysis}

In the seedling experiment, the susceptible check showed clear symptoms of the PRR infection. At the end of the experiment (23rd day), the number of plants without any PRR symptoms was counted as resistant and plants with the symptoms as susceptible. The differential expression patterns of anthocyanin of entries in the shade house were also counted and the percentage of expression pattern and correlations among anthocyanin expression pattern, disease resistance and susceptibility were calculated and presented. The anthocyanin expression patterns during differentiation and development of the plant included two types. The bidirectional expression included the appearance of pigments on the adaxial surface of mid rib of the apical leaf and on the base of the stem of the same plant, whereas mono-directional expression of the pigment included either on apical leaf or on the base of the stem of a plant.

The disease susceptibility scores recorded from 1 to 9, where $1=1$ to $10 \%$ of the plants showed symptoms of the disease as described by Vock et al. (1980), $2=11$ to $20 \%$ of plants showed yellowing of lower leaves defoliation from the ground upwards and/or wilting of entire plants, $3=21$ to $30 \%$ plants showed yellowing of lower leaves defoliation from the ground upwards and/or wilting of entire plants, and so on till $9 \geq 80 \%$ of plants showed yellowing of lower leaves defoliation from the ground upwards and/or wilting of entire plants (Fig. 1a, b). The plots were scored after

Table 1 Percentage of plants in each genotype that expressed anthocyanin pigment; $\mathrm{A}++=$ Expression of anthocyanin at the base of the stem and on the apical leaf axis,
6 weeks of growth in the field by assessing the visible symptoms, mostly wilted or dead (Fig. 1a, b), as mentioned in the second paragraph of this document's introduction. The seed yield per plot recorded $(\mathrm{g})$ for both field experiments $(7 \times 7$ and $5 \times 5)$, were analysed as per respective models shown above and presented here. The data on disease score of the field trials $(5 \times 5$ and $7 \times 7)$ were subjected to transformation (Arc sign) before analysis to meet the assumptions of the analysis. The final disease scores and the seed yields (g/plot) data from $5 \times 5$ and $7 \times 7$ Row Column (Alpha Lattice) design experiment were analysed as Row Column Alpha Design using SAS or $\mathrm{R}$ as per the model shown above.

\section{Results}

The test entries showed higher $(P<0.05)$ level of resistance and higher $(P<0.05)$ seed yield/plot than their respective controls in the separate tests. The results of the shade house trial are shown in a bar chart (Fig. 2). Many plants had red pigmentation (Anthocyanin) on base of the stem. Some plants had the pigment on the adaxial surface of the apical leaf and some plants had expressed the pigment on both parts of the plant. The number of plants that had anthocyanin expression in th plants were summarised in Table 1. The relationship between anthocyanin expression pattern and disease resistance was summarised in Table 2. The disease scores and plot yields (g) of the field experiments were shown in Tables 3 and 4. The strip chard, ANOVA and Heat maps for seed yield (g) were shown in "Appendices 2 and 4 " and in Figs. 3 and 4 for the $5 \times 5$ and $7 \times 7$ field

$\mathrm{A}+-=$ Expression of anthocyanin only at the base of the stem, $\mathrm{A}-+=$ Expression only in the apex leaf, and $\mathrm{A}--$ no expression in any part of the plant

\begin{tabular}{|c|c|c|c|c|c|c|}
\hline Serial \# & Genotype & Pedigree & $\mathrm{A}++$ & $\mathrm{A}+-$ & $\mathrm{A}-+$ & $\mathrm{A}--$ \\
\hline 1 & CICA 512R & $\mathrm{JIMBOUR} \times \mathrm{ICC} 14903$ & 66.7 & - & - & 33.3 \\
\hline 2 & CICA 722 & 8952-1Q × $99002($ JIMBOUR x ICC12004) & 85.7 & 14.3 & - & - \\
\hline 3 & CICA 804 & $94-012 * 98 \mathrm{~V} 4006 \times \mathrm{JIMBOUR}$ & 85.7 & 14.3 & - & - \\
\hline 4 & CICA 807 & YORKER × F1 $01176($ JIMBOUR × 90102-5Q-1093) & 60 & 40 & - & - \\
\hline 5 & CICA 808 & YORKER $\times$ F1 $01179($ JIMBOUR $\times$ S95425 & 50 & 50 & - & - \\
\hline 6 & Jimbour & Jimbour & - & 30 & 70 & - \\
\hline 7 & Amethyst & Amethyst & 33.3 & - & - & 66.7 \\
\hline
\end{tabular}


Table 2 Correlation among anthocyanin expression pattern, disease resistance and susceptibility $(\mathrm{n}=7)$

*Correlation coefficien significant at $\mathrm{P}=0.05$

\begin{tabular}{|c|c|c|c|c|c|c|}
\hline & \multicolumn{6}{|c|}{ Plants with pigmentation pattern } \\
\hline & $\mathrm{A}++$ & $A+-$ & $\mathrm{A}-+$ & A-- & Healthy & Susceptible \\
\hline $\mathrm{A}++$ & 1 & & & & & \\
\hline $\mathrm{A}+-$ & -0.21 & 1 & & & & \\
\hline $\mathrm{A}-+$ & $-0.79 *$ & 0.20 & 1.00 & & & \\
\hline $\mathrm{A}--$ & -0.21 & -0.70 & -0.24 & 1.00 & & \\
\hline Healthy & $0.75^{*}$ & -0.18 & -0.26 & -0.48 & 1.00 & \\
\hline Susceptible & $-0.92 *$ & -0.05 & 0.83 & 0.27 & -0.66 & 1 \\
\hline
\end{tabular}

Table 3 Summary of 1 analysis of chickpea single plant bulks trial conducted in a $5 \times 5$ - Alpha lattice design with two replications, screened in the phytophthora root rot disease-screening nursery

\begin{tabular}{|c|c|c|c|c|c|}
\hline Entry no & Genotype/ID & Pedigree & Disease score & Plot yield $(\mathrm{g})$ & Rank \\
\hline 1 & CICA0608 & SONA4028 $\times$ JIMOUR & 2.2 & 229 & 12 \\
\hline 2 & CICA0801-1 & YORKER $\times 94-012 * 98 \mathrm{~V} 4006$ & 2.3 & 275.5 & 5 \\
\hline 3 & CICA0801-2 & YORKER $\times$ 94-012*98V4006 & 2.2 & 313.5 & 3 \\
\hline 4 & CICA0801-3 & YORKER $\times 94-012 * 98$ V4006 & 2.2 & 273.5 & 6 \\
\hline 5 & CICA0801-4 & YORKER × 94-012*98V4006 & 1.7 & 246.5 & 10 \\
\hline 6 & CICA0802 & Syn-1447 YORKER $\times$ 94-012*98V4006 & 2.2 & 236 & 11 \\
\hline 7 & CICA0803 & $94-012 * 98 \mathrm{~V} 4006 \times 90102-5 \mathrm{Q}-1072$ & 2.4 & 124 & 23 \\
\hline 8 & CICA0805 & LIPPER $\times$ S95344 & 1.2 & 267.5 & 7 \\
\hline 9 & CICA0806 & YORKER $\times$ F1 o1176 (JIMBOUR X90102-5Q-1093 & 3.4 & 174 & 21 \\
\hline 10 & CICA0807-1 & YORKER $\times$ F1 o1176 (JIMBOUR X90102-5Q-1093 & 1.6 & 207.5 & 17 \\
\hline 11 & CICA0807-2 & YORKER $\times$ F1 o1176 (JIMBOUR X90102-5Q-1093 & 3 & 223.5 & 14 \\
\hline 12 & CICA0807-3 & YORKER $\times$ F1 o1176 (JIMBOUR X90102-5Q-1093 & 1.7 & 224.5 & 13 \\
\hline 13 & CICA0807-4 & YORKER $\times$ F1 o1176 (JIMBOUR X90102-5Q-1093 & 1.8 & 205.5 & 18 \\
\hline 14 & CICA0811 & $($ YORKER $\times$ FLIPPER $) \times$ MOTI & 1.9 & 200.5 & 19 \\
\hline 15 & CICA0812-1 & $($ YORKER $\times$ FLIPPER $) \times$ MOTI & 2.6 & 214.5 & 15 \\
\hline 16 & CICA0812-2 & $($ YORKER $\times$ FLIPPER $) \times$ MOTI & 2.5 & 319.5 & 1 \\
\hline 17 & CICA0813-3 & $($ YORKER $\times$ FLIPPER $) \times$ JIMBOUR & 2.6 & 251.5 & 9 \\
\hline 18 & CICA0813-19 & $($ YORKER $\times$ FLIPPER $) \times$ JIMBOUR & 2.9 & 290 & 4 \\
\hline 19 & Jimbour Bold & Jimbour selection for seed size & 4.1 & 148.5 & 22 \\
\hline 20 & Yorker & Yorker & 2.2 & 266.5 & 8 \\
\hline 21 & Amethyst & Amethyst & 6.3 & 50.5 & 24 \\
\hline 22 & Jimbour & Jimbour & 3.1 & 213.5 & 16 \\
\hline 23 & CICA0512 & CICA0512 & 3.4 & 179 & 20 \\
\hline 24 & CPI56564 & CPI56564 & 2.6 & 316 & 2 \\
\hline 25 & C. reticulatum & C. reticulatum & 1 & 0 (late) & 25 \\
\hline Mean & & & 2.5 & 227.1 & \\
\hline $\mathrm{CV}$ & & & 18.3 & 8.4 & \\
\hline CD 0.05 & & & 1.4 & 10.6 & \\
\hline
\end{tabular}

The disease scoring system consisted of 1-9 scale where $1=$ resistant and $9=$ highly susceptible

experiments respectively. The experimental designs showed the fixed row, column arrangements and the allocation of entries at random in each plot. Heat maps offered visual summary of information of the field experiment. It gave a two-dimensional representation of the data using colours. The heat map chart helped to 
Table 4 Summary of chickpea single plant selection trials conducted in a $7 \times 7$-row column design (Alpha lattice) after analysis showing mean plot yield $(\mathrm{g})$, and ranks of test entries

\begin{tabular}{|c|c|c|c|c|c|}
\hline Entry no & Genotype/ID & Pedigree & Disease score & Plot yield (g) & Rank \\
\hline 1 & CICA0511-1 & JIMBOUR $\times$ ICCC3996 & 3 & 172.5 & 30 \\
\hline 2 & CICA0512-1 & JIMBOUR $\times$ ICC14903 & 3 & 120.5 & 41 \\
\hline 3 & CICA0512-2 & JIMBOUR $\times$ ICC14903 & 6 & 23.5 & 48 \\
\hline 4 & CICA0512-3 & JIMBOUR $\times$ ICC14903 & 4.5 & 75 & 44 \\
\hline 5 & CICA0512-4 & JIMBOUR $\times$ ICC14903 & 4.5 & 49.5 & 46 \\
\hline 6 & CICA0608-1 & SONA4028 $\times$ JIMBOUR & 1 & 199.3 & 23 \\
\hline 7 & CICA0611-1 & SONA4028 $\times$ JIMBOUR & 2.5 & 179 & 28 \\
\hline 8 & CICA0611-2 & SONA4028 $\times$ JIMBOUR & 2 & 99.5 & 42 \\
\hline 9 & CICA0710-1 & WACPE2003 $\times$ MOT & 2 & 253.7 & 17 \\
\hline 10 & CICA0722-1 & JIMBOUR $\times$ 99012F1 $($ HOWZAT $\times$ ICCV96839) & 3 & 157.7 & 33 \\
\hline 11 & CICA0722-2 & 8952-1Q × $99002($ JIMBOUR $\times$ ICC12004 & 1.5 & 254.5 & 16 \\
\hline 12 & CICA0722-3-1 & 8952-1Q × $99002($ JIMBOUR $\times$ ICC12004 & 2.5 & 273 & 12 \\
\hline 13 & CICA0722-3-2 & 8952-1Q × $99002($ JIMBOUR $\times$ ICC12004 & 2.5 & 178.5 & 29 \\
\hline 14 & CICA0722-3-3 & 8952-1Q × $99002($ JIMBOUR $\times$ ICC12004 & 2 & 323.5 & 3 \\
\hline 15 & CICA0722-3-4 & 8952-1Q × $99002($ JIMBOUR $\times$ ICC12004 & 2.5 & 274 & 11 \\
\hline 16 & CICA0722-3-5 & 8952-1Q × $99002($ JIMBOUR $\times$ ICC12004 & 2 & 309 & 5 \\
\hline 17 & CICA0801-1 & F1 $01021($ YORKER $\times$ FLIPPER $) \times$ JIMBOUR & 1.5 & 454 & 1 \\
\hline 18 & CICA0802-1-1 & YORKER $\times 94-012 * 98 V 4006$ & 2 & 302 & 6 \\
\hline 19 & CICA0802-1-2 & YORKER $\times 94-012 * 98$ V4006 & 2 & 265 & 15 \\
\hline 20 & CICA0803-2-1 & $94-012 * 98 \mathrm{~V} 4006 \times 90102-5 \mathrm{Q}-1072$ & 1.5 & 186 & 27 \\
\hline 21 & CICA0803-2-2 & $94-012 * 98 \mathrm{~V} 4006 \times 90102-5 \mathrm{Q}-1072$ & 3 & 167 & 31 \\
\hline 22 & CICA0803-3-1 & $94-012 * 98 \mathrm{~V} 4006 \times 90102-5 \mathrm{Q}-1072$ & 2.5 & 310.5 & 4 \\
\hline 23 & CICA0803-3-2 & $94-012 * 98 \mathrm{~V} 4006 \times 90102-5 \mathrm{Q}-1072$ & 2.5 & 245 & 18 \\
\hline 24 & CICA0803-3-3 & $94-012 * 98 \mathrm{~V} 4006 \times 90102-5 \mathrm{Q}-1072$ & 2.5 & 354.5 & 2 \\
\hline 25 & CICA0803-3-4 & $94-012 * 98 \mathrm{~V} 4006 \times 90102-5 \mathrm{Q}-1072$ & 3 & 146 & 38 \\
\hline 26 & CICA0803-1-1 & $94-012 * 98 \mathrm{~V} 4006 \times 90102-5 \mathrm{Q}-1072$ & 2 & 208 & 21 \\
\hline 27 & CICA0803-1-2 & $94-012 * 98 \mathrm{~V} 4006 \times 90102-5 \mathrm{Q}-1072$ & 1.5 & 289 & 9 \\
\hline 28 & CICA0803-2-3 & $94-012 * 98 \mathrm{~V} 4006 \times 90102-5 \mathrm{Q}-1072$ & 3 & 156 & 34 \\
\hline 29 & CICA0803-2-4 & $94-012 * 98 \mathrm{~V} 4006 \times 90102-5 \mathrm{Q}-1072$ & 3 & 206 & 22 \\
\hline 30 & CICA0803-3-5 & $94-012 * 98 \mathrm{~V} 4006 \times 90102-5 \mathrm{Q}-1072$ & 2 & 295 & 5 \\
\hline 31 & CICA0803-4 & $94-012 * 98 \mathrm{~V} 4006 \times 90102-5 \mathrm{Q}-1072$ & 2 & 218 & 20 \\
\hline 32 & CICA0804-1 & 94-012*98V4006 $\times$ JIMBOUR & 2 & 190 & 24 \\
\hline 33 & CICA0805-1 & FLIPPER $\times$ S95344 & 2.5 & 152 & 37 \\
\hline 34 & CICA0808-1 & YORKER $\times$ F1 $01179($ JIMBOUR $\times$ S95425 $)$ & 2.5 & 278 & 11 \\
\hline 35 & CICA0809-1 & YORKER $\times$ F1 $01179($ JIMBOUR $\times$ S95425 $)$ & 3.5 & 187.5 & 25 \\
\hline 36 & CICA0809-3-1 & YORKER $\times$ F1 $01179($ JIMBOUR $\times$ S95425) & 5 & 165.5 & 32 \\
\hline 37 & CICA0809-3-2 & YORKER $\times$ F1 $01179($ JIMBOUR $\times$ S95425 $)$ & 2.5 & 268.5 & 13 \\
\hline 38 & CICA0812-1-1 & F1 $01021($ YORKER $\times$ FLIPPER $) \times$ MOTI & 2 & 266 & 14 \\
\hline 39 & CICA0812-1-2 & F1 $01021($ YORKER $\times$ FLIPPER $) \times$ MOTI & 5.5 & 38 & 47 \\
\hline 40 & CICA0814-1 & JIMBOUR $\times$ 99039-1013 & 2.5 & 153 & 35 \\
\hline 41 & CICA0815-1-1 & JIMBOUR $\times$ CICA0512 & 3.5 & 240 & 19 \\
\hline 42 & CICA0815-1-2 & JIMBOUR $\times$ CICA0512 & 3.5 & 129.5 & 40 \\
\hline 43 & CICA0816-1-1 & $97 \mathrm{C} 016-9 \times 99038-1013$ & 2.5 & 145 & 39 \\
\hline 44 & CICA0816-1-2 & $97 \mathrm{C} 016-9 \times 99038-1013$ & 6.5 & 61.7 & 45 \\
\hline
\end{tabular}


Table 4 continued

\begin{tabular}{|c|c|c|c|c|c|}
\hline Entry no & Genotype/ID & Pedigree & Disease score & Plot yield (g) & Rank \\
\hline 45 & CICA0816-1-3 & $97 \mathrm{C} 016-9 \times 99038-1013$ & 2 & 123.5 & 49 \\
\hline 46 & CICA0818-1 & CICA0511 × 99038-1013 & 2 & 295.5 & 7 \\
\hline 47 & Jimbour-Bold & Jimbour-selection for seed size & 2.5 & 187.5 & 25 \\
\hline 48 & Amethyst & Amethyst & 5.5 & 99.5 & 42 \\
\hline \multirow[t]{4}{*}{49} & Jimbour & Jimbour & 4.5 & 153 & 35 \\
\hline & Mean & & 2.8 & 202.2 & \\
\hline & $\mathrm{CV}$ & & 6.1 & 29.4 & \\
\hline & CD 0.05 & & ns & 20.3 & \\
\hline
\end{tabular}

This trial was screened in the phytophthora root rot disease-screening nursery at Hermitage research station

visualize complex yield performance comparison of different genotypes across rows and columns and reps in this experiment. Here the darker colour was used for higher values and lighter colour for lower values.

ANOVA summarised the analysis of variance for seed yield.

\section{Seedling test in shade house}

The shade house tests consistently, showed the highest level of disease resistance in all except one test entry. The susceptible check Amethyst showed clear disease symptoms (Fig. 1d), which confirmed that the pathogen was present, virulent and the inoculum density required for infection was sufficient in the medium used. Both resistance and susceptibility were evaluated based on the visual symptoms as described by Vock et al. (1980), which were mentioned in the earlier sections of this document. Among the five test entries, genotypes, CICA512R, CICA722, CICA804, CICA807 showed 100\% mean resistance (Fig. 2). Whereas CICA808 showed $73 \%$ mean resistance, when compared to Jimbour with $78 \%$ and Amethyst $27 \%$ mean resistance to the disease, at the end of the seedling test (Fig. 2). The survival percentage of the susceptible check, Amethyst was significantly lower $(P<0.05)$ than all test entries of the shade house test, and it consistently displayed disease symptoms in all the three replications, which indicated that the soil from PRR screening nursery had virulent pathogens with sufficient spore density to infect the susceptible varieties and the last test was valid.

The plants that revealed bidirectional expression of the anthocyanin pigment, that was on the adaxial surface of mid rib of the apical leaf and on the base of the stem, seemed to have highest level of resistance, compared to plants with mono-directional expression (either at the base of the stem or on the adaxial surface of the apical leaf) of the pigment. The preliminary data on the expression pattern of anthocyanin pigment was recorded and presented here in Table 1 and their correlation with disease resistance are shown in Table 2.

Screening of single plant bulks in the field trial

All the test entries (18) of the bulked single plant trial $(5 \times 5)$ showed significantly higher $(P<0.05)$ disease resistance than the standard susceptible check Amethyst (Table 3). Three test entries (5) CICA08014, (10) CICA0807-1 and (12) CICA0807-3, indicated equal or significantly higher $(P<0.05)$ level of resistance than the standard resistant control variety (entry 22) Jimbour. The control Yorker (entry 20) tend to perform better than the standard resistant check with a score of 2.2 and a yield of $266.5 \mathrm{~g} / \mathrm{plot}$ than the best resistant check Jimbour (entry 22) which had a 3.1 score and $213.5 \mathrm{~g} /$ plot.

The mean disease scores ranged from 1.0 for Cicer reticulatum (entry 25) to 6.3 for the susceptible check, Amethyst (entry 21) in the single plant bulked $(5 \times 5)$ test (Table 4$)$. When plot yield was considered, the highest $(P<0.05)$ seed yield was $319 \mathrm{~g}$ for the entry 16 , CICA0812-2, which ranked 1 with a disease score of 2.5 and the lowest seed yield was $50.5 \mathrm{~g}$ for the entry 21, Amethyst ranked 24th. The seed yield of entry 25, Cicer reticulatum could not be assessed due to its requirement for long duration for flowering.

The 18 test entries of $5 \times 5$ Alpha lattice trial originated from 10 families (breeding lines from same 
Fig. 5 The Phytopthora root rot disease incidence mean scores of common genotypes over three years of testing. Genotypes on X axis and scores on $\mathrm{Y}$ axis. Each plot scored on a scale of $1-9$, where 1 is resistant and 9 is susceptible. The tests over three seasons were same for the field, season, the strains of pathogen, procedure of inoculation, cultural practices and person who scored the disease incidence. These scores are from the common genotypes in S3 METs, first year in blue bars, second year in red bars and third year in green bars. The image a for the single plant bulks trial in 5 x 5 Alpha lattice design and the image $\mathbf{b}$ for the single plant trial in $7 \times 7$ Alpha lattice design

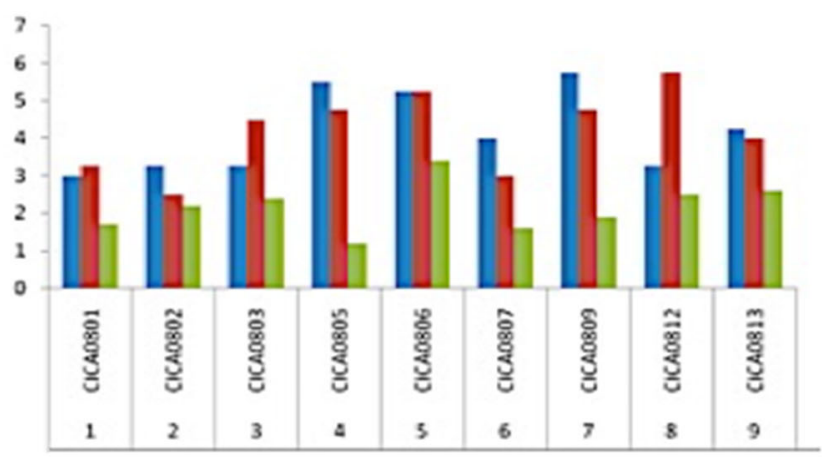

(a)

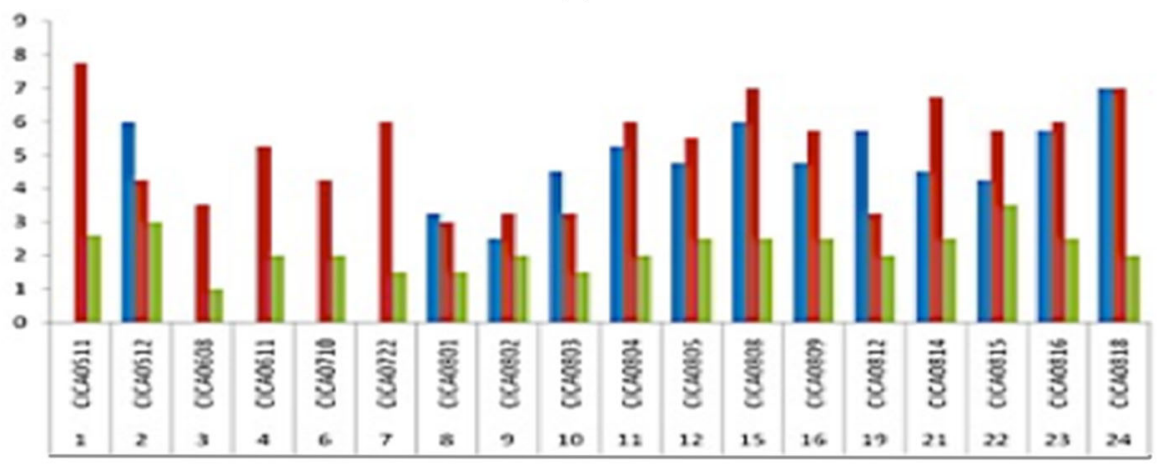

(b) cross). The family members ranged from one to four test entries (Table 3). The family of CICA0801, consisting of four members, recorded the highest family mean plot yield $(277.25 \pm 13.77 \mathrm{~g} / \mathrm{plot})$. It also included two highest yielding test entries of the trial. All the entries in this family showed good resistance to the disease in the field screening and they were 2.3, 2.2, 2.2 and 1.7 (Table 3).

The family of CICA0807 consisting of four members recorded the lowest family mean plot yield $(215.25 \pm 5.07 \mathrm{~g} / \mathrm{plot})$. Surprisingly, all the members of this family showed good resistance to the disease in the field screening trial, with scores of 1.6, 3.0, 1.7 and 1.8 (Table 3). The entry CICA0805 of the single plant bulks trial recorded the highest resistance score of 1.2 among test entries with an average plot yield of $276 \mathrm{~g} / \mathrm{plot}$, which ranked 7th among 25 test entries.

The disease scores of common genotypes over 3 years of testing, under similar conditions of testing were also examined. This was summarised in Fig. 5a, b for $5 \times 5$ and $7 \times 7$, which had common entries with previous two seasons. This comparison, even though farfetched, indicated that the single plants selection reduced the disease susceptibility considerably, when compared to the plants from whole plot selection (Fig. 5a, b) that was done in the previous two seasons.

Screening of single plants in the field trial

Among 46 test entries of the $7 \times 7$ trial, 42 of them inclined to have better resistance to the disease than the standard resistant check Jimbour. (Table 4). The 46 test entries originated from 17 families (breeding lines of same cross). The number of breeding lines within the families of the $7 \times 7$ trial, ranged from 1 to 12 test entries (Table 4). The mean disease scores ranged from 1 to 6.5 in this test (Table 4). The susceptible check, Amethyst's score was 5.5 with 42nd rank for plot yield.

The family of CICA0802, consisting of two members, recorded the highest family mean plot yield of $283.5 \pm 26.16 \mathrm{~g} /$ plot among the 17 families. Both the entries in this family also showed highest resistance to the disease in the field screening with mean disease score of 2 (Table 4). The family CICA0512 consisting of four members recorded the lowest family mean plot yield of $67.13 \pm 28.0 \mathrm{~g} / \mathrm{plot}$, which was surprisingly lower than the susceptible check yield ( $99.5 \mathrm{~g} / \mathrm{plot})$. However, the family members displayed higher level 
of resistance with a disease score of $4.5 \pm 0.6$, than standard check's disease score of 5.5.

While the independent comparisons between entries for plot yield was considered, there were 37 test entries, which yielded higher than $(P<0.05)$ the susceptible check Amethyst and 29 test entries, which yielded higher than $(P<0.05)$ the standard resistant check Jimbour. The only highest seed yielding entry was \# 17- CICA 0812-2, which had $454 \mathrm{~g} /$ plot (1st rank). This yield was significantly $(P<0.05)$ higher than 23 other entries (Table 3). It had a mean disease score of 1.5 . The entry 6-CIC0608-1 with highest resistance having a disease score of 1.0, yielded only $199.3 \mathrm{~g} /$ plot with 23rd rank for plot yield. However, it was significantly $(P<0.05)$ higher than the seed yield (153 g/plot) of the standard resistant check Jimbour.

A comparison of common test entries evaluated in the previous two seasons and the corresponding single plant entries of $7 \times 7$ trials are given in Fig. 5b. The single plants selection reduced the disease susceptibility considerably, when compared to the entries that originated from whole plot screening of the previous two seasons.

\section{Discussion}

The high level of resistance and seed yield among the progenies of selected resistant single plants in relevant trials and the death of susceptible checks, confirmed that the selected resistant single plants were not escaped from the pathogenesis in the field trial (NCMET-Stage 3). These single plant progenies resisted the entry and/or proliferation of the pathogen in vivo. In all the three trails conducted, with the seeds of the selected single plants, the susceptible check consistently displayed the symptoms of the diseases as described by Vock et al. (1980). Many plants originated from the single plant selection also offered higher seed yield $(P<0.05)$ than the best resistant check, Jimbour in both field trials. These confirmed that the pathogen was virulent and the inoculation density was sufficient for all the trials conducted with the seeds of selected single plants. This also established that the three tests were valid, reproducible and justified. The fact that the disease resistance level of single plant selections was higher than that of whole plot selection, deserves for new selection approaches in resistance breeding.
The relationship between anthocyanin and PRR resistance reported here was new in chickpeas. (Figure 1c and Tables 1, 2), which needed to be investigated further. Such protective roles of this pigment, both against plant diseases (Dixon 2001; Bovy et al. 2007) and physical stresses (Smillie and Hetherington 1999) were conveyed earlier. In addition, the role of this pigments was also reported, by $\mathrm{Lu}$ et al. (2017), Rosado-Álvarez et al. (2014), Liu et al. (2013), Maddox et al. (2010), Treutter (2006), Steyn et al. (2002) and Nicholson and Hammerschmidt (1992), in safeguarding the plant growth and development. Many breeders have used the pigmentation as a marker for disease resistance.

Wegulo et al. (1998) and Li et al. (2009) effectively utilised pigmentation to screen soybean-breeding lines against white mould (Sclerotinia sclerotiorum), both in the laboratory and in the field conditions. Whereas Kolkman and Kelly (2000) used this in common bean against white mould. The pea (Pisum sativum L) breeders once considered that the pigmentation of flower was linked to resistance genes of Fusarium rot (Fusarium solani Mart.). However, when susceptibility was observed in a pigmented variety, the pea breeders narrowed down the phenotypic selection parameters to root disease severity and root dry weight (Bodah Eliane 2014). However, the possibility of association between differential expression of the pigment and resistance was not investigated.

There is a need to establish the relationship between anthocyanin expression pattern and PRR resistance. If there is a strong relationship as indicated by this preliminary result and as established in many other crops, pyramiding of genes for anthocyanin expression can give good results for resistance. Single plant selection from the disease nursery will reduce the level of heterogeneity within population, as shown here (Figs. 3, 4), and eventually homogenous populations could be achieved. Induction of haploids and doubling chromosomes or production of double haploids of resistant single plants from early selection is another fast and efficient method to generate a homozygous resistant variety without compromising other good characters.

True or complete resistance among plants that originated from a resistant single plant was expected at this stage of the breeding program, because the single plants were selected from NCMET-S3, which consisted of plants at F7 or F8 generation. The 
cleistogamy condition existed in chickpeas ensured self-pollination. The single seed descend selection ensured higher level of homozygosity. Irrespective of the above two processes, there was considerable differences in the disease scores among the entries in the two field trials $(P>0.05)$, which consisted the seeds of the selected resistant single plants. This indicated that there was the occurrence of new genetic recombinants from the selected single mother plant/s. This confirmed that some level of heterozygocity for resistance (Tables 3,4) lasted or remained among the test entries of S1 to S3 trials. This could have been the possible cause of disease susceptibility over generations.

Alternatively, it could be assumed that there were changes in the level of virulence of the pathogen or a combination of both caused the heterogeneity. Another remote possibility for heterogeneity for resistance was that there was a new pathogen in the soil, which upon infection showed similar symptoms to that of PRR, but no such pathogen was discovered so far.

The comparison of common test entries that originated from whole plot selection (in the previous two seasons) and from single plant selection (of the third season), clearly indicated that the susceptibility score was brought down considerably among the single plant selections (Fig. 5a, b). In other words, the level of resistance was much higher in plots, where the plants originated from the single plant selection technique, when compared to plots, where the plants originated from whole plot selection technique. Even though the same person scored the trials in all three seasons and trials were conducted under similar conditions, this type of comparison from these trials may be bit far-fetched.

The disease scores and plot yields within a group of entries originated from the same cross (entries 10 to 13) also varied significantly $(P<0.05)$, in the bulked single plant trial $(5 \times 5)$. It also differed noticeably $(P>0.05)$ within such groups of the single plant trials in $7 \times 7$ lattice design (Tables 3,4$)$. These variabilities within and between groups of entries confirmed that this substantial level of heterogeneity, for PRR resistance stemmed from the zygotic condition of the single plants. These single plants were specifically selected for the resistant character.

Even though the association between the PRR scores and plot yield indicated general agreement for this single plant selection method $(\mathrm{r}=-0.78$ and -0.63 ), there were large variability with in a group of plants originated from the same cross (families) of entries in both experiments as shown above. Any level of susceptibility (a score higher than one) in any entry $(5 \times 5$ or $7 \times 7)$ indicated that the formerly selected resistant single mother plant was a heterozygote and produced new recombinants with PRR resistant and susceptible segregates, which in turn influenced the plot yield. In other words, the heterogeneity within a plot for resistance indicated the level of heterozygocity for the resistant genes within selected resistant single mother plants. Since the single plants selected for the two trials were from F7 and/or F8 generation, this kind of segregation, for PRR resistance and for the pigmentation pattern (Table 1), was not expected at this generation, if resistance was controlled by single gene. The above level of heterozygocity within the seeds used was inherent for most of the test entries in the $5 \times 5$ and $7 \times 7$ field trials. This clearly indicated that large number of genes were involved in regulating root rot resistance and PRR resistance can be recognised as quantitative in nature.

If the PRR resistance was controlled by a single gene, homozygosity could have achieved in F4 generation. The single seed descents selection, single plant selection and pedigree selection techniques in self-pollinated plants attain homozygosity in few generations, for the character of interest that was controlled by single or few genes. Usually in this kind of selection, homogeneity achieved faster in few generations than other selection techniques like mass selection or whole plot selection.

Du et al. (2013) after using a most virulent strain to screen for PRR resistance, reported that none of the chickpea lines developed from the inter-species crosses had high level of resistance. Such polygenic resistance mechanism was seen by the chickpea breeders, when they could develop only moderately resistant varieties (Knights et al. 2008). It appeared that the "moderately resistant varieties" had a heterozygotic and heterogenic component for resistance. Another point to consider was the genetic differences of virulence that might have existed among the strains of pathogens used ( $\mathrm{Du}$ et al. 2013). This might have added some level of differential pathogenicity due to competition among the nine strains. 
Single plant selection followed by repeated screening or single back cross-followed by single plant selection and repeated screening might help to achieve true or complete resistance. The screening techniques could also be modified to detect or to eliminate the interactive effects of differential pathogenicity of PRR strains. The plot yield was significant $(P<0.05)$ in both experiments (Appendix 2a and 4a). This was a clear image of the higher variability within and between entries (genotypes) or plots, which was higher than the field (environmental) variability. This indicated a polygenic resistance mechanism was acting among the genotypes tested.

Polygenic resistance mechanisms were reported for chickpea Fusarium wilt (Upadhyaya et al. 1983) and other crops (Götesson et al. 2002; Narayanan et al. 2009; Li et al. 2010). If many genes were involved in imparting resistance to PRR, selections should be made from very advanced generations (Falconer et al. 1996), otherwise both resistant and susceptible components would get progressed in the absence of a selection pressure. A selection pressure is essential at every step when developing resistant varieties. It is a well-accepted fact that genetic uniformity of final product is crucial in every crop production, processing and marketing steps of an agriculture or horticultural system.

The concerns of lower rhizobial colonization of PRR resistant varieties and reliance of $\mathrm{N}$ and $\mathrm{P}$ from soil (Plett et al. 2016) need more elaborate agronomic research. As there wee many diverse species $(>100$ spp.) of rhizobia (Marta et al. 2014; Dekkiche et al. 2017) and the results of a study was inadequate to generalise rhizobial infection pattern. However, considering an approach to take account and understand the nodulation pattern of wild and cultivated varieties would, not only give insight into disease resistance but also give valuable information for breeder on drought tolerance, yield stability and climate change adaptation pattern.

When to select for a character, without genetic studies, was one of the bottlenecks breeders face during initial stages of a breeding program. The $12.5 \%$ of heterozygocity at F4 (Falconer et al. 1996) may involve about 93 million base pairs of chickpea DNA sequences (Jain et al. 2013). Since very few genes in chickpea control the favourable traits like seed size, it was possible to attain a high level of homogeneity for seed characters at an early stage of a breeding program. However, it is widely accepted by quantitative geneticists that if many genes control a specific trait, selection need to be done from very advanced generations, depending on the number of genes (Falconer et al. 1996), involved in determining the trait. The polygenic resistance as mentioned above and the findings on the mechanism of infection, Götesson et al. (2002), Narayanan et al. (2009) and Li et al. (2010), clearly indicated that breeding for resistance against this pathogen require more rigorous approaches. The use of molecular methods, such as qPCR may be used to increase the reliability of the results.

Single plant selection increased plot yield and resistance when compared to the regular checks as demonstrated here (Figs. 4, 5 and Tables 3, 4). If more cycles of single plant selection followed by disease screening is practised, the homozygous plants for resistance can be isolated. True resistance can be achieved for a crop disease as demonstrated by HajiAllahverdipoor et al. (2011), Shaikh et al. (2013) and Hanson et al. (2016) in chickpea, lentils and tomato, respectively.

Acknowledgements The author thankfully acknowledges the contributions of Ms Kelly Purnell, Mr Kristopher King, Mr William Martin, Mr Allan Lisle, Dr Rex Williams, Dr Kevin Moore, Dr Mingzhu Sun, Dr Kevin Moore, Michel Long and Dr Ian Delacy for their assistance in various ways. Thanks to Grain Research and Development Corporation, Department of Primary Industries NSW and Department of Agriculture and Forestry, Queensland for funding National Chickpea Multi Environment Trials.

\section{Compliance with ethical standards}

Conflict of interest There is no conflict of interest

Open Access This article is distributed under the terms of the Creative Commons Attribution 4.0 International License (http:// creativecommons.org/licenses/by/4.0/), which permits unrestricted use, distribution, and reproduction in any medium, provided you give appropriate credit to the original author(s) and the source, provide a link to the Creative Commons license, and indicate if changes were made.

\section{Appendix 1}

Randomization for replications 1 (R1) and 2 (R2) and heat map for seed yield $(\mathrm{g})$ per plot for single plant bulk trials in $5 \times 5$ Alpha Lattice Design with two replications (Fig. 3). 


\section{Appendix 2}

Strip chart (a) and ANOVA (b) for seed yield per plot $(\mathrm{g})$ of Alpha $5 \times 5$ lattice trial laid out in PRR disease screening nursery.

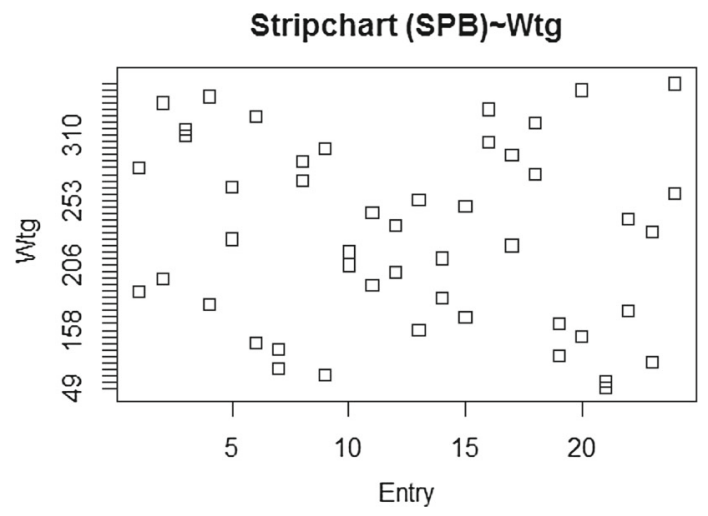

(a) Strip chart of entries in $5 \times 5$ Alpha lattice design trial consisting of progenies of resistant single plant bulks, which was laid out in PRR disease screening nursery at Hermitage Research Station.

\begin{tabular}{|c|c|c|c|c|c|}
\hline Source & Df & Sum Sq & Mean Sq & F value & $\operatorname{Pr}(>F)$ \\
\hline Entry & 24 & 183294 & 7637.2 & 3.9718 & 0.02453 \\
\hline Rep & 1 & 15243 & 15242.6 & 7.9271 & 0.02265 \\
\hline Rep:Row & 8 & 64247 & 8030.9 & 4.1766 & 0.02958 \\
\hline Rep:Column & 8 & 31116 & 3889.5 & 2.0228 & 0.16946 \\
\hline Residuals & 8 & 15383 & 1922.9 & & \\
\hline
\end{tabular}

(b) Analyses of variance table of entries in $5 \times 5$ Alpha lattice design trial consisting of progenies of resistant single plant, which was laid out in PRR disease screening nursery at Hermitage Research Station. 


\section{Appendix 3}

Randomization for replications 1 (R1) and 2 (R2) and heat map for seed yield $(\mathrm{g})$ per plot for single plant trials in $7 \times 7$ Alpha Lattice Design with two replications (Fig. 4).

\section{Appendix 4}

Stripcahrt (a) and ANOVA (b) for seed yield (g) for $7 \times 7$ Alpha lattice trial laid out in PRR disease screening nursery (Fig. 5).

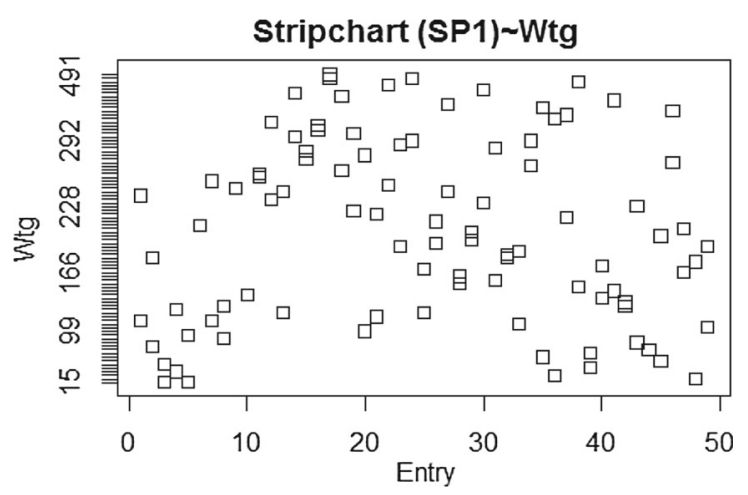

(a) Strip chart of entries in $5 \times 5$ Alpha lattice design trial consisting of progenies of resistant single plant bulks, which was laid out in PRR disease screening nursery at Hermitage Research Station.

Source Df Sum Sq Mean $\mathrm{Sq} F$ value $\operatorname{Pr}(>\mathrm{F})$

$\begin{array}{lrrrrr}\text { Entry } & 48 & 717527 & 14948.5 & 2.1647 & 0.02168 * \\ \text { Reps } & 1 & 24769 & 24769.0 & 3.5868 & 0.07036 \\ \text { Reps:Column } & 12 & 60269 & 5022.4 & 0.7273 & 0.71215 \\ \text { Reps:Rows } & 12 & 66907 & 5575.6 & 0.8074 & 0.64073 \\ \text { Residuals } & 24 & 165736 & 6905.7 & & \end{array}$

Signif. codes: '*' 0.05 ' 0.1

(b) Analyses of variance table of entries in $7 \times 7$ Alpha lattice design trial consisting of progenies of resistant single plants, which was laid out in PRR disease screening nursery at Hermitage Research Station. 


\section{References}

Bodah E (2014) Genetic mechanisms of resistance to Fusarium root rot in pea (Pisum sativum L.). ProQuest Dissertations and Theses

Bovy A, Schijlen E, Hall RD (2007) Metabolic engineering of flavonoids in tomato (Solanum lycopersicum L.) the potential for metabolomics. Metabolomics 3:399-412

Brinsmead RB, Rettke ML, Irwin JAG, Ryley MJ, Langdon PW (1985) Resistance in Chickpea to Phytophthora megasperma F. sp. Medicaginis. Plant Dis 69(2):504-506

Dekkiche S, Benguedouar A, Sbabou L, Taha K, Filali-Maltouf A, Béna G (2017) Chickpea (Cicer arietinum L.) is nodulated by unexpected wide diversity of Mesorhizobium species in Eastern Algeria. Arch Agron Soil Sci 13(7):1-13

Dixon RA (2001) Natural products and plant disease resistance. Nat Lond 411(6839):843-847

Du W, Zhao X, Raju T, Davies P, Trethowan R (2013) Studies on the resistance of some Australasian chickpeas (Cicer arietinum L.) to Phytophthora root rot disease. Aust J Crop Sci 7(6):794-800

Falconer DS, Mackay TFC (1996) Introduction to quantitative genetics, 4th edn. Longman, London

Götesson A, Marshall JS, Jones DA, Hardham AR (2002) Characterization and evolutionary analysis of a large polygalacturonase gene family in the oomycete plant pathogen Phytophthora cinnamomi. Mol Plant Microbe Interact 15(9): 907-921. Publication no. M-2002-0724$01 \mathrm{R}$

Haji-Allahverdipoor K, Bahramnejad B, Amini J (2011) Selection of molecular markers associated with resistance to 'fusarium' wilt disease in chickpea ('Cicer arietinum' 1.) using multivariate statistical techniques. Aust J Crop Sci 5(13):1801-1809

Hanson P, Lu S-F, Wang Jaw-Fen, Chen W, Kenyon L, Tan C-W, Tee KL, Wang Y-Y, Hsu Y-C, Schafleitner R, Ledesma D, Yang R-Y (2016) Conventional and molecular marker-assisted selection and pyramiding of genes for multiple disease resistance in tomato. Sci Hortic 201:346-354

Jain M, Misra G, Patel RK, Priya P, Jhanwar S, Khan AW, Shah N, Singh VK, Garg R, Jeena G, Yadav M, Kant C, Sharma P, Yadav G, Bhatia S, Tyagi AK, Chattopadhyay D (2013) A draft genome sequence of the pulse crop chickpea (Cicer arietinum L.). Plant J Cell Mol Biol 74(5):715-729

Knights EJ, Southwell RJ, Schwinghamer MW, Harden S (2008) Resistance to Phytophthora medicaginis Hansen and Maxwell in wild Cicer species and its use in breeding root rot resistant chickpea (Cicer arietinum L.). Aust J Agric Res 59:383-387

Kolkman JM, Kelly JD (2000) An indirect test using oxalate to determine physiological resistance to white mould in common bean. Crop Sci 40:281-285

Li D, Sun M, Han Y, Teng W, Li W (2009) Identification of QTL underlying soluble pigment content in soybean stems related to resistance to soybean white mold (Sclerotinia sclerotiorum). Euphytica 172:49-57

Li X, Han Y, Teng W, Zhang S, Yu K, Poysa V, Anderson T, Ding J, Li W (2010) Pyramided QTL underlying tolerance to Phytophthora root rots in mega-environments from soybean cultivars 'Conrad' and 'Hefeng 25'. Theor Appl Genet 121(4):651-658

Liu ZH, Liu YX, Pu ZE, Wang JR, Zheng YL, Li YH, Wei YM (2013) Regulation, evolution, and functionality of flavonoids in cereal crops. Biotechnol Lett 35(11):1765-1780

Lu Y, Qi CYB, Rui L, Suxiao H, Jie Z, Ji T, Yuncong Y (2017) Flavonoid accumulation plays an important role in the rust resistance of Malus plant leaves. Front Plant Sci 18(8): 1286

Maddox CE, Laur LM, Tian L (2010) Antibacterial activity of phenolic compounds against the phytopathogen Xylella fastidiosa. Curr Microbiol 60(1):53-58

Manning B, Ackland S, Moore K, Lucy M, Brinsmead B (2000) Best practice management for sustainable production: Chickpea. New South Wales Agriculture, Orange

Marta L, Ana A, Solange O (2014) Legume growth-promoting rhizobia: an overview on the Mesorhizobium genus. Microbiol Res 169:2-17

Misk A, Christopher F (2011) Biocontrol of chickpea root rot using endophytic actinobacteria. BioControl 56(5):811-822

Mitchell JW, Baker RJ, Knott RJ (1982) Evaluation of honeycomb selection for single plant yield in durum wheat. Crop Sci 22(4):840-843

Narayanan NN, Sehiza G, Tasma IM, David G, Randy S, Bhattacharyya MK (2009) Identification of candidate signaling genes including regulators of chromosome condensation 1 protein family differentially expressed in the soybean-Phytopthora sojae interaction. Theor Appl Genet 118:399-412

Nicholson RL, Hammerschmidt R (1992) Phenolic compounds and their role in disease resistance. Annu Rev Phytopathol 30:369-389

Parlevliet JE (2002) Durability of resistance against fungal, bacterial and viral pathogens; present situation. Euphytica 124:147-156

Plett JM, Plett KL, Bithell SL, Mitchell C, Moore K, Anderson PJR, Ian C (2016) Improved Phytophthora resistance in commercial chickpea (Cicer arietinum) varieties negatively impacts symbiotic gene signalling and symbiotic potential in some varieties. Plant Cell Environ 39(8): 1858-1869

Poland JA, Balint-Kurti PJ, Wisser RJ, Pratt RC, Nelson RJ (2009) Shades of grey: the world of quantitative disease resistance. Trends Plant Sci 14:21-29

Rhodes LH, Mayer DK (1989) Effects of seed treatment with metalaxyl or pyroxyfur on damping-off of alfalfa caused by Phytophthora megasperma f. sp. medicaginis. Crop Prot 8(5):369-372

Rosado-Álvarez C, Leire MR, Rodríguez A, Rocío BUM (2014) Antifungal activity of asparagus extracts against phytopathogenic Fusarium oxysporum. Sci Hortic 171:51-57

Shaikh R, Axel D, Myrtle H, Jennifer A, Robert LC, Lone B (2013) New sources of resistance to Colletotrichum truncatum race $\mathrm{Ct} 0$ and $\mathrm{Ct} 1$ in Lens culinaris Medikus subsp. Culinaris obtained by single plant selection in germplasm accessions. Genet Resour Crop Evol 60:193-201

Sharma M, Ghosh R (2016) An update on genetic resistance of chickpea to ascochyta blight. Agronomy 6:18 
Smillie RM, Hetherington SE (1999) Photoabatement by anthocyanin shields photosynthetic systems from light stress. Photosynthetica 36:451-463

Stack JP, Miller RL (1985) Relative survival potential of propagules of Phytophthora megasperma f. sp. medicaginis. Am Phytopathol Soc 75(9):1025-1031

Steyn WJ, Wand SJE, Holcroft DM, Jacob G (2002) Anthocyanins in vegetative tissues: a proposed unified function in photoprotection. New Phytol 155:349-361

Thakare RB, Qualset CO (1978) Empirical evaluation of singleplant and family selection strategies in wheat. Crop Sci 18(1):115-118

Treutter D (2006) Significance of flavonoids in plant resistance: a review. Environ Chem Lett 4:147

Tyler BM (2007) Phytophthora sojae: root rot pathogen of soybean and model oomycete. Mol Plant Pathol 8:1-8

Upadhyaya HD, Smithson JB, Haware MP, Kumar J (1983) Resistance to wilt in chickpea. II. Further evidence for two genes for resistance to race 1. Euphytica 32(3):749-755
Vander plank JE (2012) Disease resistance in plants. Elsevier, Philadelphia

Vlachostergios DN, Lithourgidis AS, Roupakias DG (2011) Effectiveness of single-plant selection at low density under organic environment, a field study with lentil. Crop Sci $51: 41-51$

Vock NT, Langdon PW, Pegg KG (1980) Root rot of chickpea caused by Phytophthora megasperma var. sojae in Queensland. Aust Plant Pathol 9:117

Walton JD (1994) Deconstructing the cell wall. Plant Physiol 104:1113-1118

Wegulo SN, Yang XB, Martinson CA (1998) Soybean cultivar responses to Sclerotinia sclerotiorum in Field and controlled environment studies. Plant Dis 82:1264-1270

Publisher's Note Springer Nature remains neutral with regard to jurisdictional claims in published maps and institutional affiliations. 